Tesis. Año 14, 13(17), 2020, 141-154

\title{
Antología del grabado del sur peruano Primer panorama del grabado en el interior del país
}

\author{
Helberth Mendoza Laura \\ Llaqtaymanta5@gmail.com
}

\section{Resumen}

La producción plástica de grabado más allá de Lima ha sido incierta y desconocida por mucho tiempo. En el año 2003 surge una muestra anual de grabado en Cusco que progresivamente ha agrupado artistas y hermanado escuelas de arte de diversas regiones del país, por más de quince años. El 2015 todos estos esfuerzos se volcaron en la exposición titulada ANTOLOGÍA DEL GRABADO DEL SUR PERUANO.

El presente artículo aborda el análisis de la muestra que ofreció un amplio y variado panorama de una de las expresiones artísticas más significativas del sur del Perú, donde se resume las obras de los grandes maestros del grabado contemporáneo sureño. Expuesta en el Centro Cultural Inca Garcilaso del Ministerio de Relaciones Exteriores en Lima en marzo y mayo del 2015. La importancia de este estudio consiste en mostrar el desarrollo e impacto logrado con la exposición.

Palabras clave: Antología, grabado, sur peruano, panorama, exposición.

\section{Abstract}

The plastic production of engraving beyond Lima it has been uncertain and known in a lot of time, is in the year 2003 that arises an annual sample of engraving in Cusco that progressively it has grouped artists and related schools of art of diverse regions of the country, for more than fifteen years. in 2015 all these efforts were summarized on the exhibition entitled "ANTHOLOGY OF THE ENGRAVING OF THE PERUVIAN SOUTH”

The present article it approaches the analysis of the sample that offered a wide and varied panorama of one of the most significant artistic expressions of the south of Peru, which summarizes the works of the great masters of southern contemporary engraving. Exhibited at the Inca Garcilaso Cultural Center of the Ministry of Foreign Affairs in Lima in March and May 2015. The importance of the study consists of showing the development and impact achieved with the exhibition.

Key words: Anthology; Engraved,; south Peruvian,; panorama,; exhibition. 


\section{Antología del grabado del sur peruano Primer panorama del grabado en el interior del país}

\section{Introducción}

La producción plástica de grabado más allá de Lima (referida al interior del país) ha sido incierta y desconocida por mucho tiempo, además de ser poco estudiada, opacada casi siempre por la producción limeña, hasta la creación de la escuela de arte en Cusco en 1951; acontecimiento con el que enrumba su propio camino cimentado en un contexto rico de cultura y tradición, sembrándose las primeras semillas del grabado entre las paredes rudimentarias del Cusco, hasta echar raíces en la casona del Marqués Valleumbroso (Escuela de Bellas Artes) en Calle Marqués No 271, Cusco. El taller de grabado cusqueño inició teniendo como equipo una prensa alemana Krause y algunas piedras litográficas adquiridas en 1956 de un alemán de nombre Winkler. Inicialmente se laboraban grabados calcográficos y en relieve, más adelante litografía; todo ello a dirección del grabador Abraham Cano Luza, artista y docente que había estudiado y reforzado sus conocimientos de grabado en la Escuela Nacional de Bellas artes de Lima. Desde la creación del taller el 4 de diciembre de 1982, empujados por el maestro Mariano Fuentes Lira, Abraham Cano Luza, Inocencio Chávez y Emiliano Franco, se crea la especialidad de grabado en la Escuela Superior Autónoma de Bellas Artes Diego Quispe Tito. Desde ese momento el grabado cusqueño emprende con mucha fuerza un camino progresivo a paso firme, buscando florecer esta noble técnica desde el Cusco, teniendo claro que esta técnica no es menos ni más que las demás expresiones artísticas, sino igual. Durante mucho tiempo el grabado estuvo al servicio de la imprenta y la publicidad; ligado con aspectos comerciales. Lo que indudablemente llevó a progresar esta tradicional técnica, pero al mismo tiempo aha mantenido alajada de otras expresiones plásticas por su característica principal que es la reproducción. En Lima por las décadas de los 70 y 80 , el grabado se empleó con mucha intensidad en la reproducción de pinturas de grandes maestros, lo que empujó aún más su desarrollo y la creación de talleres: un aparente desarrollo, pero aún no emprendía un ca- 
mino propio como expresión. Estas circunstancias y reflexiones hicieron que el grabador cusqueño tomara nuevos rumbos alejándose de la reproducción y realizando obras desde el grabado como tal; porduciendo estampas originales y con ediciones limitadas que han permitido que el grabado alcance grados superiores, gracias a la iniciativa y empuje de los maestros que la dirigieron; "Esta situación nos permitió reflexionar con mucha fuerza para emprender un despegue, proyectando el grabado en grados superiores a las experiencias iniciales” (Taller, 2015. Pág. 2).

Una de las formas de entender el desarrollo del grabado en diferentes zonas del país donde se imparte y práctica, es mediante sus muestras, exposiciones individuales o colectivas que se organizan cada cierto tiempo. En Lima quizá la entidad más relevante que ha dedicado al apoyo y difusión del grabado es el Instituto Cultural Peruano Norteamericano (ICPNA). Ls muestras de grabado organizadas por esta institución son de las expresiones con mayor tiempo de difusión; desde 1965, año en el que se realiza el Primer Salón de Grabado Peruano en Lima y los posteriores hasta el $35^{\circ}$ Salón Nacional de Grabado del 2016, año en el que se realizó la 5ta Bienal de Grabado. Siendo la más ambiciosa hasta el momento, logrando gran acogida en las exposiciones locales e internacionales. Cusco no se queda atrás, los años comprendidos entre 1986 y 1988 fue la cede de dos grandes acontecimientos en el grabado peruano; se organizaron las Bienales de Grabado que contaron con la presencia y participación de maestros del arte peruano como: Fernando de Szyslo, Augusta Barreda, Carlos Bernasconi y José Huerto Wong; estas realizadas gracias al auspicio de la galería Borkas, la Escuela de Bellas Artes del Cusco y el Taller de Grabadores Cusco. Los eventos fueron de tal importancia y trascendencia que titularon al Cusco como Capital del grabado peruano, en las páginas del diario el Comercio de Lima ese mismo año. En 1999 se funda los Encuentros Nacionales del Grabado a iniciativa de dos colegas grabadores: Lucio Vita Gutiérrez docente de Bellas Artes Cusco y Carlos Quispe Carrizales docente en Bellas Artes de Lima (docentes activos de arte). Se realizaron, durante más de seis años, integrando grabadores del país e instituciones donde se impartía esta disciplina. Pero son los Salones de Grabado Contemporáneo Cusqueño creados en 2003 - a iniciativa del artista y profesor Lucio Vita Gutiérrezque han marcado la verdadera pauta sobre el grabado, mostrando la labor que realizan los grabadores del Cusco y el sur del país en sus once salones a nivel nacional e internacional y una exposición determinante llamada: Antología del Grabado del Sur Peruano, en la que se mostraron las obras en toda su plenitud y donde se reunieron los maestros del grabado sureño de diferentes ciudades como Cusco, Ayacucho, Puno, Arequipa y Tacna. Todo ello con el propósito de difundir el grabado local y nacional. 


\section{Antología del grabado del sur peruano}

El gran logro y esfuerzo de los diferentes salones de grabado contemporáneo cusqueño desarrollados hasta el momento se vuelca en la gran exposición titulada: Antología del grabado del sur peruano, expuesta por primera vez en el Centro Cultural Inca Garcilaso del Ministerio de Relaciones Exteriores, ubicada en el Jr. Ucayali 391, del Centro Histórico de Lima, del 17 de marzo al 10 de mayo de 2015.

Muestra colectiva realizada en Lima después de casi tres décadas; aquel año de 1988 un puño pequeño de nueve grabadores: Abraham Cano Luza, Miguel Valencia Cazorla, Lucio Vita Gutiérrez Mendoza, Darwin Salas, Erasmo Salcedo, Lourdes Flores, Samuel Núñez, Vittori Von Rezzori y María Teresa Delgado expusieron sus trabajos en la galería Borkas en San Isidro (entre ellos como alumno y docente Lucio Vita, dirigidos por Abraham Cano Luza). En 2015, un grupo numeroso de grabadores, entre maestros y jóvenes dirigidos por Lucio Vita, participaron de la exposición antes mencionada, la cual fue resultado de inagotables esfuerzos para llevar y organizar la exposición por diversas regiones del país después de más de quince años.

Para la muestra se invitó artistas grabadores de diversas regiones en las que se llevaron los salones de grabado contemporáneo cusqueño; también se presentaron colecciones particulares de las cuales se seleccionó un exquisito número de obras. La selección estuvo a cargo del reconocido artista cusqueño Alberto Quintanilla del Mar, como resultado de especial esmero y esfuerzo de las principales escuelas de arte que cultivan el grabado. La Antología del grabado del sur peruano es una selección de 70 grabados de artistas provenientes de Cusco, Arequipa, Ayacucho, Puno y Tacna, presentando la producción del grabado peruano actual de maestros y jóvenes grabadores, y que reunió artistas de talla universal como Alberto Quintanilla y maestros grabadores como Abraham Cano Luza, Mariano Fuentes Lira, Miguel Valencia, Lucio Vita, Lourdes Flórez, Luis Solorio, Tania Brun, Rubén Mamani, José Lara, Ysabel Clot, Edward de Ibarra, Alberto Ramos, Fredy Mendoza, Boris Castillo, Betzabeth Paniagua, Gloria Quispe, Artemio García, Tania Chura, Shirley Mamani, entre otros.

Las obras presentadas en esta muestra colectiva datan de varios años atrás, entre los grabados más antiguos, figuran calcografías y xilografías monocromas de Mariano Fuentes Lira (Cusco, 1904-1986) fundador de la Escuela superior Autónoma de Bellas Artes "Diego Quispe Tito" de Cusco, en el que se muestra su comprometida convicción con el indigenismo.

Otra xilografía con tema indigenista es la del maestro Abraham Cano Luza (Cusco, 1936-2016) fundador de la especialidad de grabado en la ya mencionada Escuela, el cual mostró una de sus xilografías monocromas: un paisaje de excelente acabado titulado Huasao, en el que se aprecia su destreza en el mane- 
jo dinámico de las incisiones generadas por las gubias, logrando un armonioso contraste del blanco y negro, exaltando la fachada de la capilla dentro de un cielo con nubes algodonadas: en el primer plano se observa un portón de piedras de estilo inca y dos columnas coloniales que sostienen una pequeña construcción, dando paso al segundo plano que ocupa la fachada clásica de una capilla con dos campanarios, una cruz y tejados estilizados de características grotescas pero agradables a la vista. Es la representación de la capilla de Huasao. (Fig. 1)

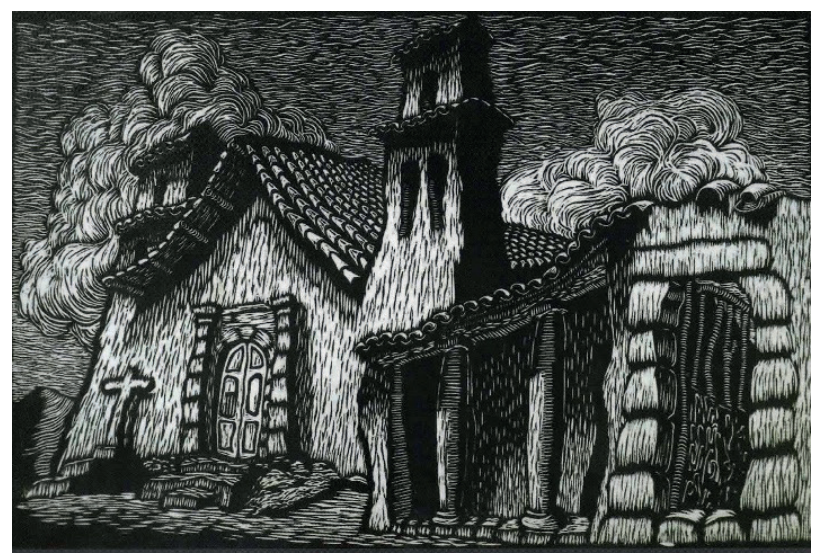

Fig. 1. Capilla de Huasao, S/F. Xilografía. Autor: Abraham Cano Luza.

Otro de los maestros de la exposición es el cusqueño Miguel Valencia Cazorla (Cusco 1917-2002), impactando con sus exóticas xilografías monócromas de corte indigenista y gran destreza técnica; las obras de Valencia mostraron una secuencia de tres escenas costumbristas de su tierra natal Tinta, (Danza Qanchi, Sara Tipiy Pacha, Carnaval Qashwa). El primero detítulo Danza Qanchi, es una xilografía monocromática coloreada en soporte de papel que muestra en el primer plano a cinco personajes con abundantes movimientos corporales: los dos personajes próximos al espectador del primer plano llevan similar indumentaria portando una vara; el personaje del medio lleva una indumentaria con pelaje y gorra con cabellera, mientras que los dos personajes que se ubican atrás llevan instrumentos musicales. La escena trata de una de las danzas tradicionales de la provincia de Canchis; son los qanchis de Mamue$\mathrm{ra}$ - con pazos y movimientos eufóricos, los personajes portan una vara en la mano derecha con sus clásicas monteras de estos lados-, acompañados de un extrovertido pablito protector del Apu Qoyllurrit'i, quien porta un zurriago danzando al compás de los infaltables músicos que acompañan con su alegre wankartinya (bombo de cuero) y flauta dulce. La escena se ubica en la plaza de Tinta frente a la iglesia; escena a la que acompañan y enmarcan seres mitológicos andinos comprendidos por aves, felinos y serpientes (Fig. 2). La otra xilografía monocroma del mismo autor, de formato vertical se muestra en el primer 
plano a tres hombres ataviados portando instrumentos musicales de cuerdas entre sus manos y a tres mujeres también ataviadas que acompañan a este grupo con evidentes movimientos de sus extremidades; se trata de la escena del tradicional Qashwa carnavalesco conocido como contrapunto en Tinta, donde el hombre y la mujer se responden a manera de discusión cantando y bailando alegremente al compás de la bandurria con su típica indumentaria, ubicándose la escena frente a la iglesia de Tinta. (Fig. 3)

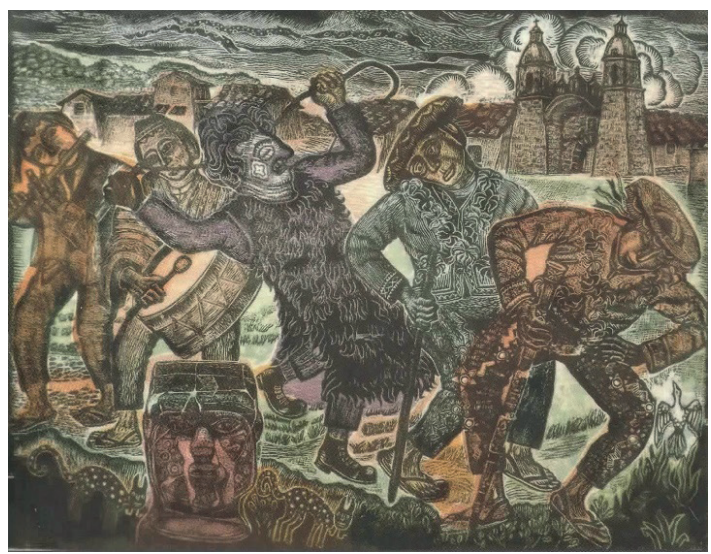

Fig. 2. Qanchis de Mamuera, 1979. Xilografía coloreada. Autor: Miguel Valencia Cazorla.

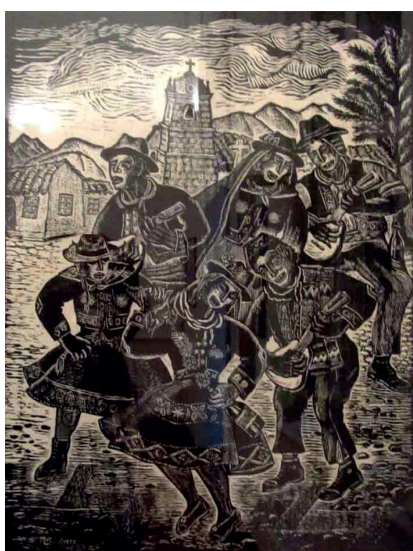

Fig. 3. Qhaswa carnaval, 1990. Xilografía.

Autor: Miguel Valencia Cazorla.

Si hablamos de litografías, se mostraron cuatro espectaculares estampas: Sihuayro, La Charrettey Campo florido de Alberto Quintanilla del Mar (Cusco 1934- ?) producidas en Atelier 17, taller fundado por el británico Stanley William Hayter. Son litografías que muestran el mundo fantástico andino de Quintanilla, de estilo surrealista. El primero titulado Campo florido, en formato vertical y gama de sienas claros y oscuros muestra en el primer plano a dos personajes principales que son el hombre y el animal cuadrúpedo: el animal es un canino con dos hocicos, el primero direccionado al lado derecho y el otro al frente con los ojos circulares grandes, la nariz humanizada y los dientes filudos en posición de ataque, mostrando su agresividad ante el hombre que se soporta en forma arremolinada; el humano expresa una calma y tranquilidad levantado dos extremidades como aplacando la ferocidad del canino, mientras el tercer brazo sostiene un vaso; fuera de los dos personajes, acompañan otros pequeños humanoides de apariencia siniestra de dos caras en diversas acciones: uno sobre la cabeza del ser, el otro sobre el lomo del canino y el tercero flotando en la parte superior como vislumbrando la escena. De acuerdo a sus características y posiciones se trata del dialogo de un perro con un ser divino, generando una extraña sensación subjetiva de ensueño (fig. 4). La otra litografía en gama de azules también muestra seres antropomorfizados: en el primer plano a un ser 
de dos caras y varias extremidades, así como una guitarra y dos caninos con dos hocicos; dentro de un fondo fantástico, el hombre con las bocas ligeramente abiertas toma con un brazo un insecto gigante de ocho extremidades que se aproxima por la parte superior, mientras otras dos extremidades superiores rasga su cabeza como si se tratara de dudas e incertidumbre; entre tanto, las otras dos extremidades sostienen la guitarra. En el lado izquierdo, el primer canino antropomorfizado se encuentra sentado mirando plácidamente el rostro del hombre mientras sus brazos arpegian los acordes del instrumento musical; el otro canino que también se encuentra sentado levanta las patas delanteras observando al lado izquierdo y el otro ojo al espectador. Extraña relación de seres fantásticos de ensueños expresadas por el artista con gran maestría. (fig. 5). Estos monstruos, según el mismo testimonio de Quintanilla, reflejan el mundo onírico mágico andino de las vivencias de su infancia: seres mitológicos y demonios internos que libera en cada expresión plástica.

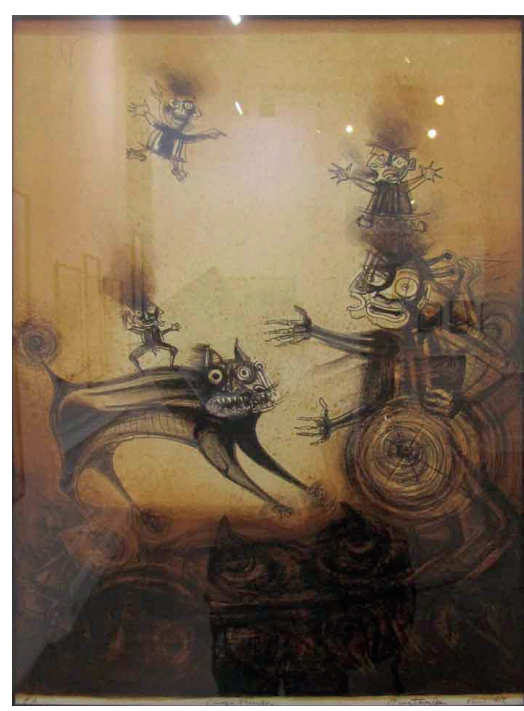

Fig. 4. Campo florido, 1969. Litografía. Autor: Alber to Quintanilla del Mar.

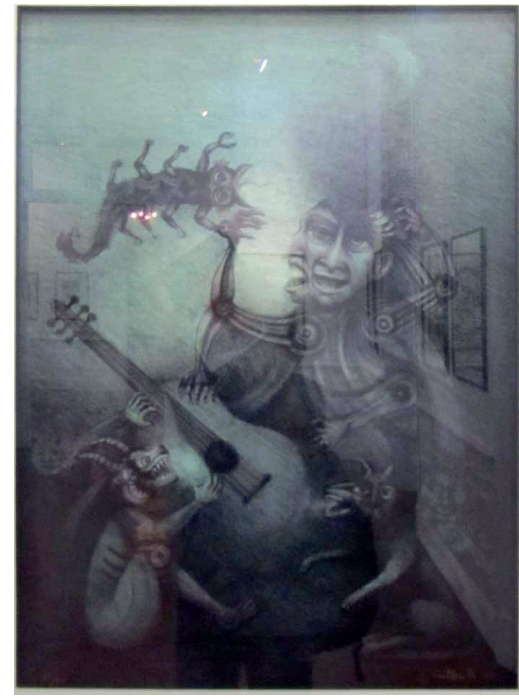

Fig. 5. S/T ,1966. Litografía. Autor: Alberto Quintanilla del Mar.

Tacna se hizo presente con las magistrales xilografías monocromas de recargados y delicados trazos lineales del maestro Alberto Ramos Palacios (Nazca, 1953- ?) ganador del XXII salón Nacional de grabado de 1987, organizado por el ICPNA. Ramos Palacios presentó la serie de "Huallallus" conformada por seis xilografías monocromas: Huallallu I dios devorador (fig. 6), Huallallu II dios devorador, Huallallu III dios devorador, Huallallu IV dios devorador, Huallallu V dios devorador y Huallallu VI dios devorador. Huallallu I es una xilografía monocroma de formato horizontal en el que se aprecia una figura predominante oscura, contrastado en un fondo blanco con una gran variedad de texturas conformados por líneas y puntos. La figura es completamente es- 
tilizada, siendo irreconocible, pero se pueden distinguir la cola como aletas de pez, el cuerpo en el que predomina un espiral y cabeza con dos ojos y las fauces que se tragan un elemento pequeño; al mismo tiempo, se aprecia en la parte superior derecha dos formas serpenteadas que van en dirección izquierda: se trata de una deidad de la cosmovisión andina, un dios tutelar Huanca, un apu representado en una aparente forma de pez que se traga a otro pequeño.

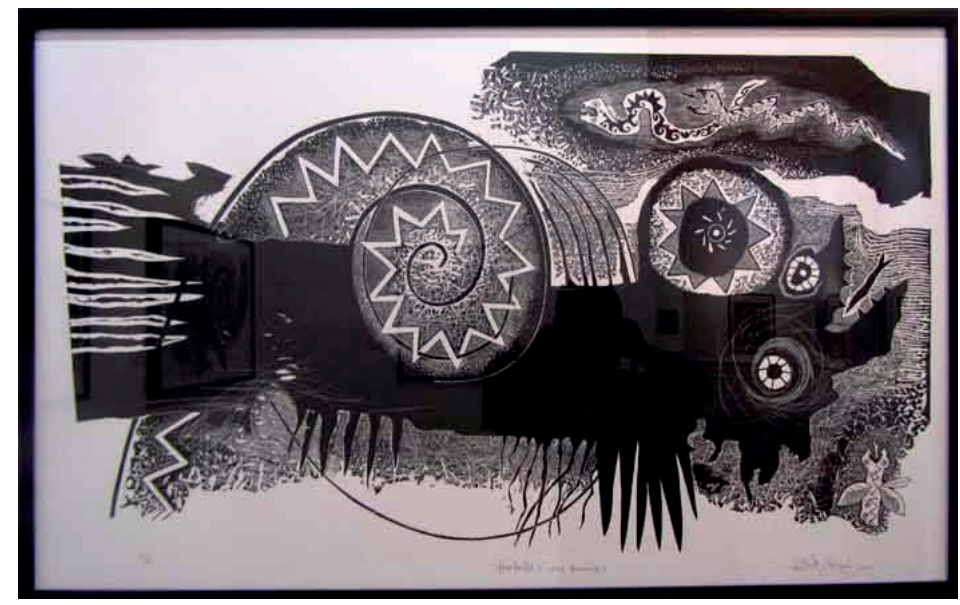

Fig. 6. Huallallu 1, dios volador, 2015. Xilografía.

Autor: Alberto Ramos Palacios.

Ganador de la segunda Bienal de grabado organizado en Cusco en 1988 es el maestro Lucio Vita, artista de reconocida trayectoria, - represente en varias oportunidades del Cusco con sus magistrales grabados de genero onírico y estilo surrealista. Vita presentó cuatro grabados de diversos años (Vuelo Nocturno, 1988; Metáfora del sonido, 2000; Mirando el futuro, 2012; Habitante Nocturno, 2013). Particular y diverso, en cada uno de sus grabados además se observa su continua experimentación de soportes matriz y de transferencia. El grabado que atrae la mirada causando inmediato asombro por el dominio de la complejidad técnica del grabado calcográfico en metal fue "Vuelo Nocturno" de 1988 (fig. 7), cuadro de formato vertical en gama de sienas y amarillos con seres fantásticos compuesto por tres planos pautados por la temperatura del color cálido: el primero ocupa la parte inferior de la composición en gama de sienas y lo conforman el torso de cuatro seres con indumentaria oscura de cabeza estilizada y mirada tétrica, con la boca abierta y diversas expresiones. Tres de ellos miran al frente y uno resalta más que los demás por los bustos circulares claros; la parte media es el segundo plano teniendo el predominio de la gama de amarillos: lo conforma un caballo estilizado con la piel clara texturada con formas ovoides, este soporta a una mujer desnuda en colores agrisados también estilizada en dirección izquierda y se encuentra recostadasobre el animal. Además tiene los ojos vendados y su parte intima cubierta por un instrumento musical de cuerdas. Detrás de ellos, una edificación antigua deformada con bal- 
cón amarillo y tejado de color siena. En el tercer plano superior, por encima del tejado en gama de sienas se observa un ser de cuerpo no reconocible flotando en dirección derecha, de su cuerpo nacen varios apéndices que se desvanecen en el fondo: la cabeza tiene un ojo circular grande y una boca que se traga instrumentos musicales. La escena trata de cuatro músicos chumbivilcanos ataviados que amansan al caballo y encandilan a una mujer en un atardecer nocturno, llevando ciegamente a la mujer con los sonidos que liberan los instrumentos musicales como el charango y el waqra phuku. Al fondo, por los cielos, en gama de sienas, se aprecia a un espíritu de los andes conocido como el habitante nocturno.

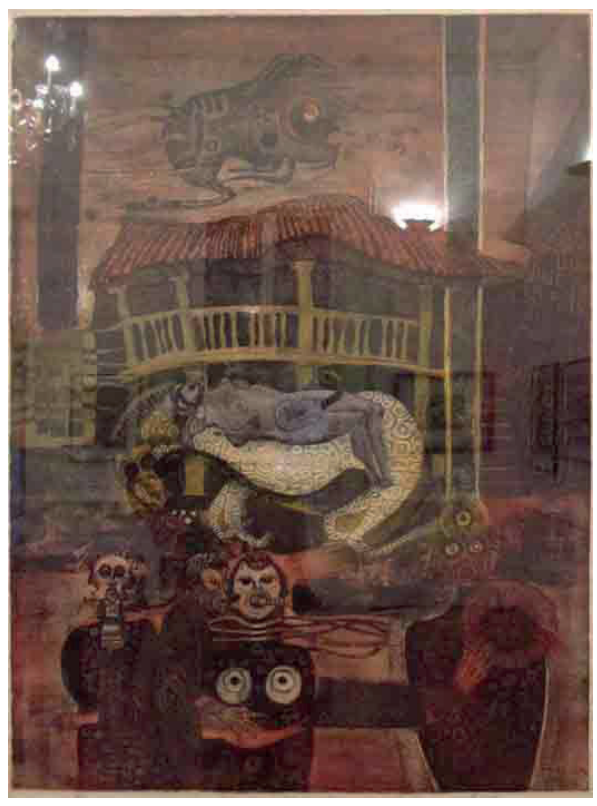

Fig. 7. Vuelo nocturno, 1988. Calcografía. Autor: Lucio Vita Gutiérrez Mendoza.

Puno estuvo representado con la xilografía del maestro grabador Rubén Mamani, actual docente de grabado de la UNA Puno. Mamani presento una xilografía monocroma indigenista de incisiones expresivas titulada Jilacata (autoridades) correspondiente al 2014 (fig. 8), en el que se aprecia cuatro individuos sentados en un banco ataviados con sombrero, chalina y poncho; porta uno de ellos una banda. Esta escena se encuentra encerrada por un fondo lineal como si fuera un cuadro pequeño; detrás de esta escena rectangular se aprecia otra escena que enmarca todo el cuadro: en el que se ve la parte superior de cinco individuos con sombrero y poncho, todos de espalda; la escena representa a autoridades indígenas Aymaras llamados Jilacatas, también conocidos como Mallku, que es la máxima autoridad de un ayllu; es característico que el mallku porte un sombrero, chalina y poncho. 


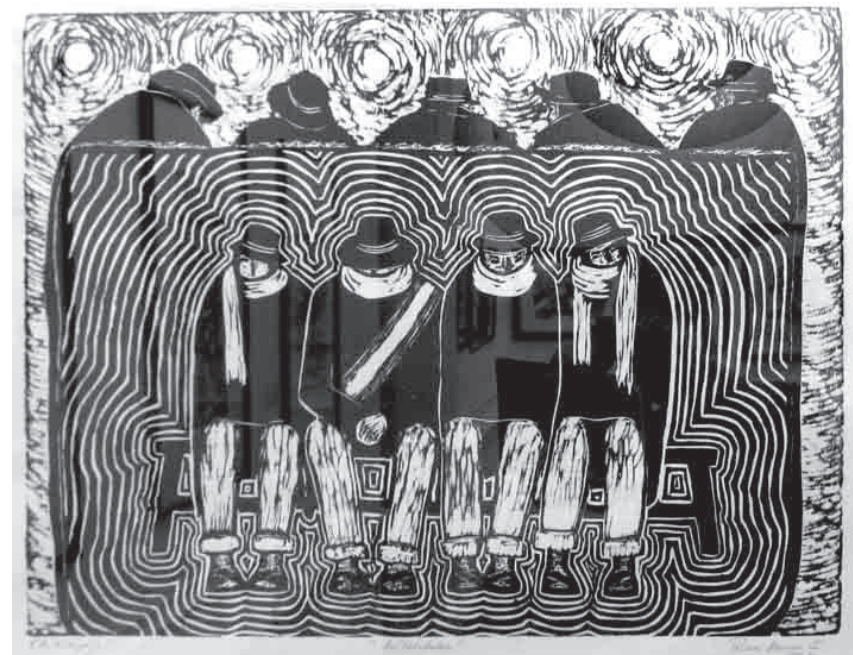

Fig. 6. Jilacata (autoridades), 2014. Xilografía. Autor: Rubén Mamani.

Arequipa se hizo presente con la xilografía monocroma del maestro José Lara Quilla, docente de la UNSA (Universidad Nacional de San Agustín de Arequipa). Presentóuno de sus temas recurrentes; un paisaje titulado Tingo viejo, edición correspondiente al 2015.Se aprecia en su xilografía el panorama conformado por el tronco y ramas de cinco arboles que dejan ver en su fondo una población que contrasta con la oscuridad del cerro. Lara representa por medio de la xilografía el paisaje de la villa de Tingo vista desde un ángulo, evidenciando su destreza en sus incisiones que son sueltas y expresivas. (Fig. 9)

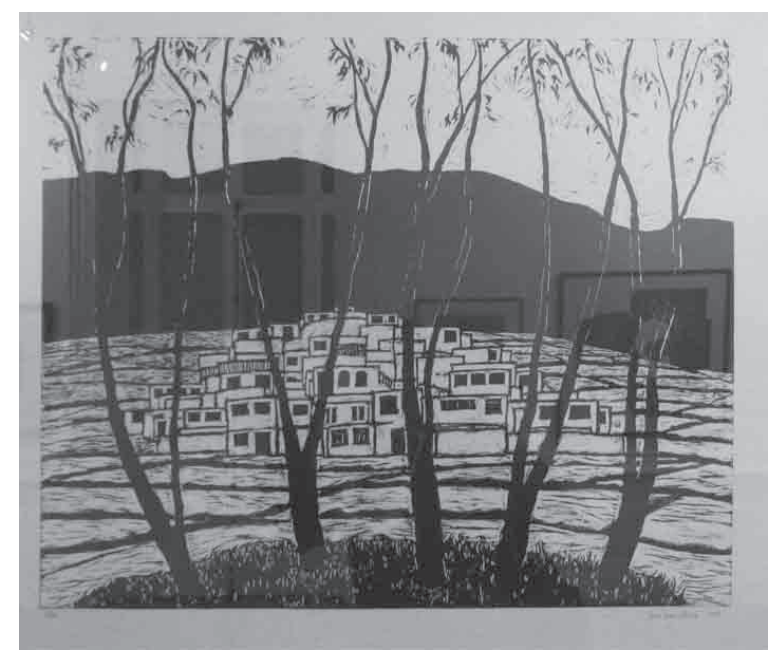

Fig. 9. Tingo viejo, 2015. Xilografía.

Autor: José Lara Quilla. 
Otra de las xilografías que resaltaron en la exposición es el paisaje andino monocromo del maestro Luis Solorio Paredes - nacido en Cusco pero que radica en Arequipa, habiendo estudiado en Lima en PUC, donde actualmente labora. Su xilografía, de evidente temática indigenista, es expresiva, resolviendo con gran maestría los contrastes a través de incisiones sueltas y sencillas que corresponden a su sello personal (como en pintura y grabado). (fig. 10)

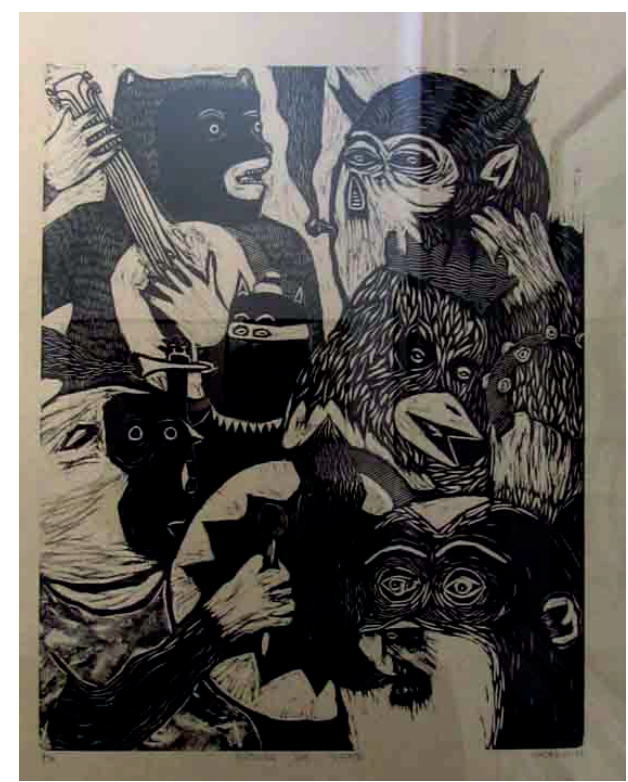

Fig. 11. Músicos de combi, 2014. Xilografía. Autor: Edward de Ybarra.

Un joven valor en el grabado arequipeño Edward de Ybarra, impresionó en esta muestra con xilografías monocromas, de animales de zoológico tocando diversos instrumentos musicales con mucha gracia y creatividad. Este grabado de gran formato titulado Músicos de combi deja ver a un mono tocando el bombo, un oso tocando la guitarra, un gallo con una pandereta, un búho y otros animales con diversas expresiones alegres que cantan (fig. 11).

Las obras se presentaron en diversos procedimientos del grabado tradicional: xilografías, litografías, intaglios, con diferentes recursos alternativos propios de la experiencia del artista. La mayoría de los grabados presentados fueron monocromos y en algunos casos grabados policromos; la temática fue también variada, se observó desde retratos, paisajes, mitos y alegorías, así como temas oníricos enriquecidos con motivos e iconografías andinas; la existencia de esta variedad de técnicas, temas y estilos hicieron que la muestra fuera exquisita. El espectador limeño disfruto de la muestra quedando impactados con 
las posibilidades del grabado. Dentro de la galería se oyó comentarios del espectador como: ...waooo, ¿esto es grabado? El público quedó impresionado de ver algo distinto, en algunos casos confundiéndolo con pinturas o fotografías; quedaron sorprendidos por la existencia de esta expresión artística. De esta manera se evidencio el poco conocimiento de la existencia del grabado como expresión plástica. Y mucho menos que es un arte que se estudia. Siesto sucede en Lima, donde hay mayor conocimiento y difusión de las artes, imaginemos en el interior del país... Hay mucho por hacer, y una de ellas es a través de las exposiciones en todo ámbito de nuestro país. El director del Centro Cultural Inca Garcilaso quedó complacido, mostrando su gran interés y apoyo al apreciar obras en grabado que casi nunca veía en sus instalaciones, manifestando que estaría dispuesto a apoyar con la difusión de los mismos.

E1 artista plástico Lucio Vita Gutiérrez ofreció, el 25 de marzo del 2015, la conferencia "Desafíos y vigencia del grabado en Cusco", donde hablo sobre la realidad del grabado cusqueño en la actualidad, llevando a una reflexión al público asistente.

\section{Conclusión}

La labor de difusión de los salones de grabado contemporáneo cusqueño por más de diez años rinde su fruto en esta muestra, siendo una gran exposición por la presencia de maestros grabadores de varias regiones del sur del Perú, resultado de años de trabajo y hermanamiento de escuelas de arte a través de sus representantes que continuamente contribuyen al grabado nacional.

La importancia de esta muestra fue trascendental, siendo una de las primeras exposiciones que permitieron ver el verdadero panorama del grabado en el interior del país, que hasta el momento (2015) no se tomaba en cuenta; no se sabía el verdadero desarrollo del grabado en las diversas escuelas más allá de Lima. Esta muestra fue una ventana que atrajo miradas de instituciones e investigadores, como es el caso del historiador y crítico de arte Manuel Munive Maco, quien no desaprovecho la oportunidad de investigar e incluir en la agenda de la 5ta Bienal Internacional de Grabado 2016, organizada por el ICPNA; de esta manera evidenció el desarrollo del grabado en el interior del país. El 2016, Munive se adentró en las diversas ciudades del interior, contactándose con Lucio Vita e invitándolo a participar de la Bienal, y de esta manera organizar una muestra que se denominó, EL GRABADO MÁS ALLÁ DE LIMA en la galería Pacho Fierro de la Municipalidad de Lima. Así, por primera vez se abordó e incluyó el grabado del interior del país dentro del catálogo de la 5ta Bienal Internacional de grabado que contiene 300 páginas. 


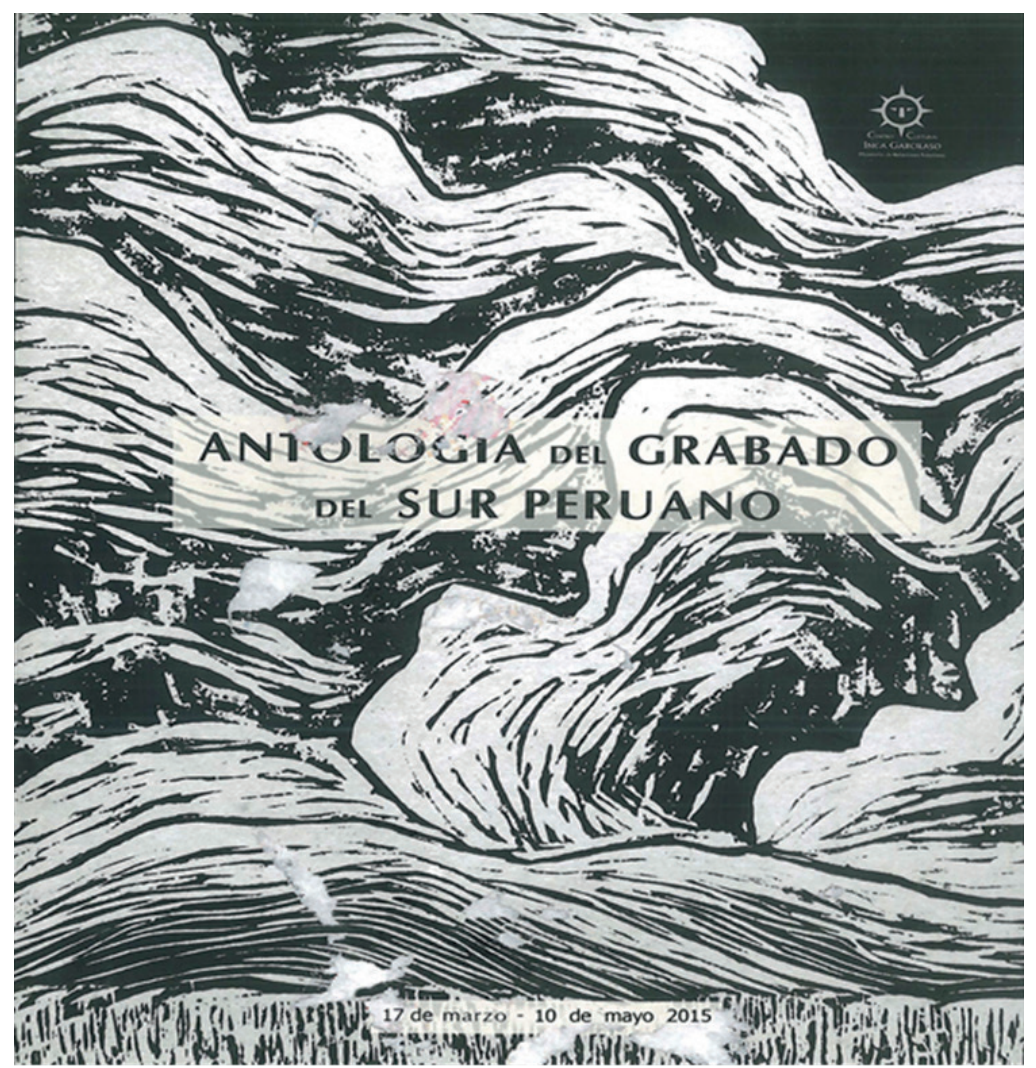

Fig 10. Catálogo: Antología del grabado del sur peruano.

Xilografía de Luis Solorio Paredes, Lima, 2015.

\section{Referencias bibliográficas}

Gutiérrez, L. V. (1996.) Ritual y vivencias mágicas religiosas del sur andino a través del grabado. (Informe técnico no publicado), Escuela Superior Autonoma de Bellas Artes del Cusco.

ICPNA (2010) 3 Bienal Internacional de Grabado IPCNA 2010. Catalogo libro. Lima: Instituto Cultural Peruano Norteamericano.

-. (2013) 4 Bienal Internacional de Grabado IPCNA 2013. Catalogo libro. Lima: Instituto Cultural Peruano Norteamericano.

-. (2016) 5 Bienal Internacional de Grabado IPCNA 2016. Catalogo libro. Lima: Instituto Cultural Peruano Norteamericano.

- (1965-2016). Archivo de Salones Nacionales de grabado ICPNA. Miraflores, Lima.

Núñez, T.S. (2002). Ensueños y fantasías a través de la litografía. (Informe técnico no publicado), Escuela Superior Autonoma de Bellas Artes del Cusco.

Quispe, F.G. (2001). Uso de materiales alternativos en el arte del grabado. (Informe técnico no publicado), Escuela Superior Autonoma de Bellas Artes del Cusco. 


\section{Catálogos y trípticos de Salones de Grabado Contemporáneo Cusqueño}

Taller de grabado ESABAC (2003) I Salón de Grabado Contemporáneo cusqueño. Catálogo de grabados. Cusco: ESABAC

Taller de grabado ESABAC (2005). II Salón de Grabado Contemporáneo cusqueño. Tríptico de grabados. Cusco: ESABAC

Taller de grabado ESABAC Catálogo (2006). III Salón de Grabado Contemporáneo cusqueño. "Homenaje al maestro Mariano Fuentes Lira" Catálogo de grabados. Cusco: ESABAC

Taller de grabado ESABAC (2007). IV Salón de Grabado Contemporáneo cusqueño Tacna - Cusco. Catálogo de grabados. Cusco: ESABAC

Taller de grabado ESABAC (2008). V Salón de Grabado Contemporáneo cusqueño Puno - Cusco. Catálogo de grabados. Cusco: ESABAC

Taller de grabado ESABAC (2009). VI Salón de Gráfica Contemporánea de la ESABAC Cusco-Oruro. Catálogo de grabados. Cusco: ESABAC

Taller de grabado ESABAC (2010). VII Salón de Gráfica Contemporánea - Potosí (Bolivia). Catálogo de grabados. Cusco: ESABAC

Taller de grabado ESABAC (2011). VIII Salón de Grabado Contemporáneo cusqueño Cusco - Trujillo. Catálogo de grabados. Cusco: ESABAC

Taller de grabado ESABAC (2013). MATRICES I, "Cusco Capital del Grabado Peruano". Catálogo de grabados. Cusco: ESABAC

Taller de grabado ESABAC (2014). MATRICES II, (X salón de grabado contemporáneo cusqueño). Encuentro de maestros y estudiantes del grabado peruano. Arequipa. Catálogo de grabados. Cusco: ESABAC

Taller de grabado ESABAC (2015). XI Salón de Grabado cusqueño Contemporáneo. "Homenaje al maestro Manuel Jesús Abraham Cano Luza". Catálogo de grabados. Cusco: ESABAC

Taller de grabado ESABAC (2015). Antología del grabado del sur peruano. Tríptico de grabados. Lima. 